\title{
Management and prognosis of uterine rupture during labor in an under-medicalized country: about 513 cases collected at the Cocody University Hospital Center (Abidjan-Cote d'Ivoire)
}

\author{
Vedi A. Loue ${ }^{1 *}$, Jean M. Dia ${ }^{2}$, Denis N. Effoh ${ }^{1}$, Roland C. Adjoby ${ }^{1}$, Joachim K. Konan ${ }^{1}$, \\ Eleonore A. Gbary ${ }^{1}$, Raphael Y. Abauleth ${ }^{1}$, Firmin Kouakou ${ }^{1}$, Serge E. Boni ${ }^{2}$
}

\begin{abstract}
${ }^{1}$ Department of Obstetrics \& Gynaecology, University Hospital of Cocody, Abidjan-Cote d'Ivoire
${ }^{2}$ Department of Obstetrics \& Gynaecology, University Hospital of Treichville, Abidjan-Cote d'Ivoire
\end{abstract}

Received: 27 August 2015

Accepted: 09 September 2015

\author{
*Correspondence: \\ Dr. Vedi A. Loue, \\ E-mail: drlouevedi@yahoo.fr
}

Copyright: ( $)$ the author(s), publisher and licensee Medip Academy. This is an open-access article distributed under the terms of the Creative Commons Attribution Non-Commercial License, which permits unrestricted non-commercial use, distribution, and reproduction in any medium, provided the original work is properly cited.

\begin{abstract}
Background: Even today, uterine rupture is necessary as an indicator of health status in developing countries, like Cote d'Ivoire. The objective of this study was to describe the factors influencing the management and the prognosis of this pathology in a level III maternity of a third world country.

Methods: The study was made in Cocody University Hospital Center (Abidjan-Cote d'Ivoire). A retrospective descriptive study of all women with ruptured uterus during labor managed between January 2002 and December 2014 was conducted. It covered 513 cases of uterine ruptures collected in 13 years.

Results: The overall incidence of uterine ruptures was $0.95 \%$ or 1 in 105 deliveries. Most cases occurred in women with unscarred uterus $(76.8 \%$ ) and $23.2 \%$ of women had a scarred uterus. Surgical treatment was radical by hysterectomy in $35.3 \%$ of all women. Treatment was more conservative by uterine suture in women from the communes of Abidjan and its suburbs $(71 \%)$ versus $25 \%$ of women who came from inland towns $(\mathrm{p}=0.000)$. Maternal mortality rate was $5.8 \%$ and was significantly influenced by the type of surgery $(\mathrm{p}=0.000)$, by the time of uterine rupture $(\mathrm{p}=0.000)$ and by the transportation distance $(\mathrm{p}=0.000)$. Fetal mortality was $94.1 \%$ for all women.

Conclusions: Uterine rupture still poses a major public health problem in under-developed countries. The multiplication of obstetric surgical units but also the availability of blood products and the effectiveness of free care will be a vital contribution to effectively and sustainably improve the prognosis of this serious pathology when just constituted.
\end{abstract}

Keywords: Obstetric labor complications, Uterine rupture, Hemostatic hysterectomy

\section{INTRODUCTION}

Uterine rupture (UR) is a paroxysmal obstetric labor complication that can lead to severe prognosis for the mother and her child if not immediately diagnosed and treated. It is much rarer in developed countries and it is observed there more often on scarred uterus. ${ }^{1}$ But in subSaharan Africa and others under-developed countries, it is still a major public health problem, mostly observing during parturition on unscarred uterus. ${ }^{2,3}$ It has therefore become imperative to master the various factors that may delay its care and cause obstetric drama. Indeed uterine rupture is rarely spontaneous, rarely without signs of prerupture and exceptional without risk factors and these risk factors are well known in the African context. ${ }^{4-7}$ In reality this aspect of the pathology should allow effective preventive care. However in a sub-Saharan African region weakened by wars, by the unfavorable socioeconomic conditions, by illiteracy and especially by the under medicalization, "it appears that a significant 
proportion of pregnant will always escape to this prevention." If prevention has failed and that uterine rupture occurred, its management in terms of quality should be able to improve maternal and fetal prognosis.

The general objective of this study was to contribute to reduce perinatal mortality by optimizing the management of parturition. The specific objectives were to analyze the surgical management of uterine rupture in a level III maternity hospital in a third world country like our country by presenting the case of our service, to describe the factors influencing this management and to assess its impact on the maternal and fetal prognosis.

\section{METHODS}

We conducted a retrospective descriptive study over a period of thirteen years in the University Hospital Center of Cocody (UHCC) in Abidjan-Cote d'Ivoire, from January 2002 to December 2014. During this period, 513 Women having uterine rupture during labor were identified. In Abidjan, economic capital of our country numbering about 4 million people, there are three level III maternities which the UHCC. The UHCC aims to receive and manage all gynecological and obstetric emergencies in the northern sector of Abidjan (about 22 maternity hospitals and peripheral health centers) and surrounding towns within a radius of about 200 kilometers.

For each woman, an epidemiological sheet was elaborated. In the study, keys factors studied include women characteristics (origin, mode of admission, uterine antecedent, and moment of the uterine rupture), surgical modalities depending on the transportation distance, delay between admission and surgical care and the feto-maternal prognosis. Statistical analysis of the studied variables was compared using the Chi-square test and Fisher's exact test, the result being significant for $\mathrm{p}<$ $5 \%$.

\section{RESULTS}

\section{Frequency of uterine rupture}

From January 2002 to December 2014, over of a period of 13 years, there were recorded 53,639 deliveries (all deliveries) in our department which 513 were complicated of uterine ruptures. The overall incidence of uterine rupture over this period was then $0.95 \%$; or 39 uterine ruptures per year or 1 in 105 deliveries.

\section{Women characteristics}

\section{Origin and mode of admission}

Most of parturients came from the districts of Abidjan $(76.2 \%)$. Seventy one (71) parturients $(13.9 \%)$ had been transported from more than $50 \mathrm{kms}$ to access our service.
Depending on their mode of admission, the parturients came by themselves accounted for $8.7 \%(n=45)$ and were evacuated in $91.3 \%$ of cases $(n=468)$. Among the evacuated women, $25 \%(\mathrm{n}=128)$ were in shock at admission, including 50 of 71 (or $70 \%$ ) women who came from the inland cities (Table 1).

\section{Uterine antecedent and moment of uterine rupture}

In total, about 513 parturients having ruptured uterus, 119 (23.2\%) had a scarred uterus and 394 (76.8\%) had a unscarred uterus.

The majority of women, or $72.9 \%(n=374)$, had ruptured their uterus in our maternity versus $27.1 \%(n=139)$ who had ruptured outside our service before admission. For uterine ruptures occurred in our unit, there was no significant difference between the rate of unscarred and scarred uterus $(27.7 \%$ vs $25.5 \%, \mathrm{p}=0.681)$ (Table 2$)$.

The 71 parturients evacuated from inland cities have all ruptured their uterus before admission to our unit.

\section{Specials features of management}

Surgical treatment was radical by hysterectomy in $35.3 \%$ of cases $(n=181)$ and conservative by uterine suture in $64.7 \%$ of cases $(n=332)$. The treatment was more conservative in women from the communes of Abidjan and its suburbs $(71 \%)$ versus $25.3 \%$ of women who came from inland towns $(\mathrm{p}=0.000)$ (Table 3$)$.

Gestures associated with treatment: bilateral tubal ligation resection in 51 women $(9.9 \%)$ and 5 suture of the bladder $(0.9 \%)$, ligation of the internal iliac arteries in $24 \%$ of cases $(n=123)$, ureteral anastomosis end to end in 7 cases $(1.3 \%)$. Blood transfusion has affected $95 \%$ of parturients $(n=487)$ of which $100 \%$ of patients from the inland cities and $87 \%$ of parturients from Abidjan and suburbs.

The "operative indication-surgery" average time was 135 minutes (2h15) with extremes of $23 \mathrm{mn}$ and $895 \mathrm{mn}$ (14h55mn). Among 443 women or $86.4 \%$, surgery was made more than 60 minutes after the surgical indication.

The surgical kit has been honored by the parents in $41.8 \%$ of cases $(n=214)$ and provided by the administration of UHCC in $58.2 \%$ of cases $(n=299)$. The operating room was not available in $57.06 \%$ of cases while the operating kit was available.

\section{Materno-fetal prognosis}

\section{Maternal Prognosis}

Maternal death rate was $5.8 \%$, or 30 deaths. There were fewer deaths for the conservative treatment (7/332) or $2.1 \%$ versus $12.7 \%$ or $(23 / 181)$ for radical treatment $(\mathrm{p}=$ 0,000). 
Table 1: Parturients' origin, transportation distance and mode of admission.

\begin{tabular}{|c|c|c|c|c|c|c|c|}
\hline \multirow{3}{*}{ Parturients' origin } & \multirow{3}{*}{$\begin{array}{l}\text { Transportation } \\
\text { distance (kms) }\end{array}$} & \multicolumn{4}{|c|}{ Mode of admission } & \multirow{2}{*}{\multicolumn{2}{|c|}{ Total }} \\
\hline & & \multicolumn{2}{|c|}{ Evacuated } & \multicolumn{2}{|c|}{ Non- evacuated } & & \\
\hline & & $\mathrm{n}$ & $\%$ & $\mathrm{n}$ & $\%$ & n & $\%$ \\
\hline Abidjan' municipalities & $\leq 20$ & 360 & 70.2 & 31 & 6 & 391 & 76.2 \\
\hline Abidjan'suburbs & $20-50$ & 37 & 7.2 & 14 & 2.7 & 51 & 9.9 \\
\hline Inland towns & $>50$ & 71 & 13.9 & & - & 71 & 13.9 \\
\hline Total & & 468 & 91.3 & 45 & 8.7 & 513 & 100 \\
\hline
\end{tabular}

Table 2: Unscarred and scarred uterus and place of uterine rupture.

\begin{tabular}{|lllrrrr|}
$\begin{array}{l}\text { Place of } \\
\text { uterine }\end{array}$ & \multicolumn{2}{l}{$\begin{array}{l}\text { Unscarred } \\
\text { uterus }\end{array}$} & \multicolumn{2}{l}{$\begin{array}{l}\text { Scarred } \\
\text { uterus }\end{array}$} & \multicolumn{3}{l}{ Total } \\
$\begin{array}{l}\text { Outside } \\
\text { UHCC }\end{array}$ & 109 & 27.7 & 30 & 25.5 & 139 & 27.1 \\
\hline In UHCC & 285 & 72.3 & 89 & 74.8 & 374 & 72.9 \\
\hline Total & 394 & 100 & 119 & 100 & 513 & 100 \\
\hline
\end{tabular}

Tables 4 and 5 summarize the influence of the moment of uterine rupture and the transportation distance on the maternal prognosis. It was noted fewer deaths in the group of women in labor whose rupture occurred in our unit $(2.4 \%)$ versus $15.1 \%$ for those whose rupture occurred outside $(\mathrm{p}=0.000)$ (Table 4$)$.

Table 3: Women's origin and surgical care.

\begin{tabular}{|lcccccc|}
\hline \multirow{2}{*}{$\begin{array}{l}\text { Women's origin } \\
\text { Surgery } \\
\text { Abidjan } \\
\text { and } \\
\text { suburbs }\end{array}$} & $\begin{array}{l}\text { Inland } \\
\text { towns }\end{array}$ & Total & & \\
\cline { 2 - 7 } & $\mathrm{n}$ & $\%$ & $\mathrm{n}$ & $\%$ & $\mathrm{n}$ & $\%$ \\
\hline Hysterectomy & 128 & 29 & 53 & 74.7 & 181 & 35.3 \\
\hline Rent repair & 314 & 71 & 18 & 25.3 & 332 & 64.7 \\
\hline Total & 442 & 100 & 71 & 100 & 513 & 100 \\
\hline
\end{tabular}

Maternal death rate increased from $2.3 \%$ before $20 \mathrm{kms}$ distance of transportation to $18.3 \%$ beyond $50 \mathrm{kms}$ with a significant difference $(\mathrm{p}=0.000)$ (Table 5). The identified causes of maternal death were: 11 cases of hemorrhage, 3 anesthetic accidents, 7 cases of postoperative persistent anemia and 9 cases of severe infection (postoperative peritonitis).

\section{Fetal prognosis}

There were a total of 529 newborns from 8 twin pregnancies, 2 triple pregnancies and 507 singleton pregnancies. Of the 529 newborns, 498 or $94.1 \%$ died, 31 newborns remained alive.

Table 4: Influence of the place of uterine rupture on maternal prognosis.

\begin{tabular}{|llll|}
\hline \multicolumn{4}{c}{ Place of uterine rupture } \\
& In UHCC & Outside UHCC & Total \\
\hline $\begin{array}{l}\text { Number of } \\
\text { women }\end{array}$ & 374 & 139 & 513 \\
\hline Deaths & 9 & 21 & 30 \\
\hline Death rate (\%) & 2.4 & 15.1 & 5.84 \\
\hline
\end{tabular}

Table 5: Influence of transportation distance on maternal prognosis.

\begin{tabular}{|llll|}
\hline $\begin{array}{l}\text { Transportation } \\
\text { distance (kms) }\end{array}$ & $\begin{array}{l}\text { Number } \\
\text { of } \\
\text { parturients }\end{array}$ & Deaths & $\begin{array}{l}\text { Death } \\
\text { rate }(\%)\end{array}$ \\
\hline$<20 \mathrm{~km}$ & 391 & 9 & 2.3 \\
\hline $20-50 \mathrm{~km}$ & 51 & 8 & 15.6 \\
\hline$>50 \mathrm{~km}$ & 71 & 13 & 18.5 \\
\hline
\end{tabular}

\section{DISCUSSION}

\section{Frequency}

The frequency of uterine rupture is variable and the reasons for this variability are numerous. Indeed the analysis and observation protocols are different: some establish this frequency over the number of caesarean and other relative to the number of delivery. But also it is important to clarify that the definition of uterine rupture may be responsible for variation in a study to another: some authors consider only the complete uterine rupture; others also include incomplete ruptured forms. Some studies are only about women with scarred uterus, others about unscarred uterus and/or both, and finally during pregnancy and / or during obstetric labor..$^{8-11}$ 
A review of the literature, however, indicates that in developed countries, the incidence of uterine rupture is less than $0.1 \%$ of all births and increases significantly in women with a previous caesarean section but remains between 0.2 and $0.8 \% .^{7,12-14}$ These low rates in developed countries are linked to the organization of maternities networks by enabling rapid transfer, early and optimal management of dystocia. ${ }^{1}$

Growing poverty in developing countries and their populations, the lower level of medical supervision, accumulation and persistence of uterine risk factors seem to be major factors in the significant elevation of uterine rupture frequency. The literature of black sub-Saharan Africa shows that over the past decade, the incidence of uterine rupture varies between $0.3 \%$ and $2.44 \%$. $^{2,3,15-17}$ The frequency observed in our service, reflecting developing countries' statistics is $0.95 \%$ of all deliveries with a majority of unscarred uterine rupture $(76.8 \%)$.

Given the literature, the incidence of uterine rupture is inversely proportional to the stage of development of a country. The variability of uterine rupture rate in African countries result from the same source of data, usually hospital, in reference centers at different levels of recruitment. In addition, the lack of health coverage, combined with the low density of management boards, reflects the low level of prevention of this complication. However the introduction of obstetric and neonatal emergencies care and free of certain services in the field of reproductive health (contraception, prenatal care, delivery and cesarean section) in most developing countries gives a real ray of hope to the significant reduction of obstetric complications in the coming years.

\section{Management}

The treatment of uterine rupture is surgical in order hemostatic purpose framed by hematological, fluid and electrolyte resuscitation. The therapeutic abstention difficult to observe in our context, is an option possible under cover of a very close monitoring of postpartum bleeding; in particular cases of dehiscence of asymptomatic segmental caesarean scar (or bleeding or pain, good uterine retraction) discovered after a uterus revision.

In this study, treatment was more conservative than radical $(64.7 \%$ against $35.3 \%)$, as in many African studies with uterine conservation rate from $60 \%$ to $91 \% .^{2,3,17}$ But some authors have reported a more radical than conservative treatment with hysterectomy rates of up to $78 \% .^{6}$

In general, the type of surgical care, radical or conservative with or without tubal ligations considers many factors that underlie the disparities in uterine conservation rates observed in different studies. ${ }^{1,2,10,16,18}$
In our study, the treatment was more radical in the parturients came from inland cities (75\%) against 29\% for parturients came from Abidjan and suburbs with a significant difference. Indeed, these parturients came from inland towns were all evacuated and they have been transported more than $50 \mathrm{kms}$ to access our service, bloodless in the majority of cases $(100 \%$ blood transfusion in this group, $70 \%$ in shock at admission), with local aged lesions and a sphacelus uterus or marked by significant dilacerations. They had a precarious hemodynamic status in a service where we noted a chronic lack in blood and derivatives and where the average time of the effectiveness of the surgery was $2 \mathrm{~h} 15 \mathrm{mn}$. This waiting period could sometimes reach $14 \mathrm{~h}$ because the acquisition of surgical emergency kit was very difficult (only $41.85 \%$ of the parents were able to honor their kits) and because the emergency operation room that was one at the time could be unavailable $(57.06 \%)$ for already busy despite the availability of surgical kits. The hemostatic hysterectomy in these conditions was deemed necessary and should be practiced early before it installs major bleeding disorders. Also the efficiency of the management of these patients in intensive care requires perfect hemostasis. When uterine conservation opportunities exist, a simple uterus suture was practiced with tubal ligations in some cases because of the extreme fragility of the uterus.

\section{Maternal and fetal prognosis}

The maternal mortality was $5.8 \%$. This is a very high rate but lower than most sub-Saharan African Studies. $3,6,11,15,18$ In Africa, the Maghreb, more medicalized, offers a better prognosis with case fatality rates of between $2.4 \%$ and $4.10 \%$ and in countries with high socio-economic level, maternal mortality is estimated at less than $1 \%$ of uterine rupture. $^{2,19}$ In our study, maternal prognosis was significantly influenced by the moment of uterine rupture (Table 4) and by the transportation distance (Table 5). In this study, the majority of parturients have ruptured their uterus after admission to UHCC (91.2\% versus $8.8 \%$ ). This sad fact that is probably not due to the quality of care at UHCC is mostly secondary to abusive and too late evacuations of parturients, already about to rupture. These excessive admissions result in long waiting hours and pose the problem of re-evacuation or evacuation of a level III structure to other medical centers. These parturients have often ruptured even before the start of their obstetric management or pending emergency caesarean kit. This is related to an inconsistency in the current reference-use system and that any delay at this level has a dramatic impact., ${ }^{2,5-7,18}$ However it was found less maternal death in the group of women in labor who ruptured in our unit $(2.4 \%$ versus $15.1 \%$ for ruptures out UHCC, $p=0.000)$. The management of women who ruptured at UHUC seems easier because it is generally an incomplete uterine rupture or recent ruptures with limited lesions, explaining a less severe maternal prognosis among these parturients. But also beyond $20 \mathrm{kms}$ of transportation distance before admission to our unit, the 
maternal mortality rate was multiplied by 7 . So a transportation distance of up to $20 \mathrm{kms}$ could be considered as a safety perimeter, beyond which the emergency medical evacuation will be associated constantly with darker maternal and fetal prognosis. Then a harmonious distribution of obstetric and surgical units in the country should take into account this distance.

The prognosis was also influenced by the type of treatment because more deaths were noted in the group of hysterectomies versus uterine conservation (12.7\% versus $2.1 \%, \mathrm{p}=0.000$ ) mainly due to the combination of more severe lesions in hysterectomies. Besides these factors, the prognosis was also influenced by the conditions of admission of our patients ( $25 \%$ evacuated in shock), so by the late admission, by the inadequate resuscitation equipment, and by the constant lack of blood products and derivatives. This maternal mortality remains high throughout black sub-Saharan Africa. ${ }^{3,6,15,17}$ The identified causes of maternal death in this study included bleeding, persistent anemia and infection, secondary to poor compensation of blood loss, the aseptic faults in extreme emergency, then to the noncompliance antibiotic related to poverty of our patients.

Fetal outcome was catastrophic in all. About 529 newborns, 498 or $94.1 \%$ died. The thirty one living newborns are from women who came from themselves from suburban municipalities of Abidjan and whose rupture was diagnosed after delivery. These were the cases of uterine recent rupture or uterine rupture discovered after uterine revision in the postpartum immediate period. This dark fetal prognosis is associated with delayed care, the inadequate resuscitation of newborns, confirming the general trend noted in African literature. , $6,11,19,20^{2}$

\section{CONCLUSIONS}

Uterine rupture still poses a public health problem in developing countries. The prognosis remains still dark. However it is a preventable disease because risk factors in our context and means of prevention are well known. The proliferation of obstetric surgical units well distributed on the territory with a qualified human resource and conscious but also the availability of blood products and the effectiveness of free care will be a vital contribution to effectively and sustainably improve the prognosis of this serious condition if just constituted.

Funding: No funding sources

Conflict of interest: None declared

Ethical approval: The study was approved by the Institutional Ethics Committee

\section{REFERENCES}

1. Ducarme G, Bargy S, Grossetti A, Bougeois B, Levardon M, Luton D. Prise en charge chirurgicale des hémorragies de la délivrance. Etude rétrospective. Gynecol Obstet Fertil. 2007;35(12):1209-14.

2. Abauleth YR, Koffi AK, Cissé ML, Boni S, Djahan Y, Janky E. Pronostic de la rupture utérine au cours du travail au CHU de Bouaké (Cote d'Ivoire). Med Trop. 2006;66(5):472-6.

3. Ngale RN, Gaunefet CE, Koirokpi A, Goddot Nangouma NMJ, Koe KG, Songo-Kette T, et al. Evolution des ruptures utérines à la maternité de l'hôpital communautaire de Bangui. Med Afrique Noire. 2012;59(2):65-9.

4. Abauleth YR, Koffi A, Cisse M-L, Boni S, Janky E. Comment éviter la rupture utérine au cours du travail? La Lettre du gynécologue. 2006;311:10-1.

5. Abdulkadir T, Ali O, Mehmet SE, Hatice ES, Neval YG, Talip K, Talip G. Uterine rupture revisited: predisposing factors, clinical features, management and outcomes from a tertiary care center in Turkey. Pak J Med Sci. 2013;29(3):753-7.

6. Qazi Q, Akhtar Z, Khan K, Khan AH. Woman health; uterus rupture, its complications and management in teaching hospital Bannu, Pakistan. Maedica (Buchar). 2012;49-53.

7. Fitzpatrick KE, Kurinczuck JJ, Alfirevic Z, Spark P, Brocklehurst $\mathrm{P}$, Knight $\mathrm{M}$. Uterine rupture by intended mode of delivery in UK: a national casecontrol study. PloS Med. 2012;9(3):e1001184.

8. Ofir K, Sheiner E, Levy A, Katz M, Mazor M. Uterine rupture: differences between a scarred and unscarred uterus. Am J Obstet Gynecol. 2004;191;425-9.

9. Wang YL, Su TH. Obstetric uterine rupture of the unscarred uterus: a twenty-year clinical analysis. Gynecol Obstet Invest. 2006;62:131-5.

10. Fatfouta AS, Villeroy de Galhau BJ, Dietsch AE. Eicher CD, Perrin A. Rupture utérine spontanée sur utérus sain pendant le travail: à propos d'un cas et revue de la littérature. J Gynécol Obstét Biol Reprod. 2008;37(2):200-3.

11. Eguzo KN, Umezurike CC. Rupture of unscarred uterus: a multi-year cross-sectional study from Nigerian Christian Hospital, Nigeria. Int J Reprod Contracept Obstet Gynecol. 2013;2(4):657-60.

12. Guyot A, Carbonnel M, Frey C, Pharisien I, Uzan M, Carbillon L. Rupture utérine : facteurs de risque, complications maternelles et fœtales. J Gyn Obst Biol Reprod. 2010;39(3):238-45.

13. Parent O. Rupture utérine ; prédiction, diagnostic et prise en charge. J Gyn Obst Biol Reprod. 2012;41(8):803-16.

14. Amate P, Séror J, Aflak N, Luton D. Rupture utérine pendant la grossesse. EMC [5-080-A-10].

15. Akaba GO, Onafowokan O, Offiong RA, Omonua K, Ekele BA. Uterine rupture: trends and feto-maternel outcome in a Nigeria teaching hospital. Niger J Med. 2013;22(4):304-8.

16. Nayama N, Mohamed-Alzouma I, Garba M, Idi N, Oumara M, Guede S, et al. Ruptures utérines obstétricales à la maternité Issaka Gazoby de Niamey. A propos d'une étude rétrospective de 195 
cas sur 3 ans. Médecine d'Afrique Noire. 2015;62(1):49-5.

17. Rasolonjatovo JDE, Randaoharison PG, Randrianirina JBS, Randrianarison P, Rasolofondraibe A. Prévalence des ruptures utérines à Antsirabe-Madagascar. Med Afrique Noire. 2005;52(10):525-8.

18. Nyengidiki TK, Allagoa DO. Rupture of the gravid uterus in a tertiary health facility in Niger delta region of Nigeria: a 5-years review. Niger Med J. 2011;52(4):230-4.
19. Kadowa I. Ruptured uterus in rural Uganda: prevalence, predisposing factors and outcomes. Singapore Med J. 2010;51:35-8.

20. Dwivedi S, Kumar A. Uterine rupture a retrospective analysis of referral cases at a tertiary care centre in Kanpur city. Int $\mathbf{J}$ Reprod Contracept Obstet Gynecol. 2015;4(4):1148-52.

Cite this article as: Loue VA, Dia JM, Effoh DN, Adjoby RC, Konan JK, Gbary EA, Abauleth RY, Kouakou F, Boni SE. Management and prognosis of uterine rupture during labor in an under-medicalized country: about 513 cases collected at the Cocody University Hospital Center (Abidjan-Cote d'Ivoire). Int J Reprod Contracept Obstet Gynecol 2015;4:1277-82. 